Egyptian J. of Nutrition Vol. XXXIV No. 2 (2019)

\title{
The Mixolab Parameters of Wheat/Quinoa Composite Flour and Their Relation to Quality Characteristics
}

\author{
Mohamed E. Abdel-Aziz \\ Food Science Department, Faculty of Agriculture, Cairo University, \\ Giza 12613, Egypt
}

\begin{abstract}
Effect of addition of Quinoa flour (QF) in different levels $(5,10$ and $15 \%)$ to wheat flour (WF) on the characteristics of the prepared pan bread was analyzed. Dough mixing properties, bread physical characteristics and sensory properties were evaluated. Increasing QF level in the QF/WF composites led to an increase in water absorption, dough development time, C4 and setback torque, and decrease in flour moisture, dough stability, C2, C3 and C5 when analyzed by Mixolab. The QF/WF composites produced darker bread and lower specific volume. Higher antioxidant activity and higher protein content were scored by pan bread containing QF. Bread samples prepared with QF (5, 10 and 15\%) were accepted by panelists for their aroma, crust and crumb color, taste and overall acceptability.
\end{abstract}




\section{Mohamed E. Abdel-Aziz}

\section{Introduction}

In Egypt, wheat is the most domestic grain crop utilized for bread making. Nevertheless, bread made from wheat flour is considered healthfully poor (Sabanis et al., 2009).

Due to the low quantity of wheat cultivated in Egypt and the importation of more than $90 \%$ of the domestic consumption from abroad, the use of other alternatives to wheat such as quinoa, amaranth and buckwheat was interested. Partial substitution of wheat flour by flours from non-wheat flours develops the wholesome nature of baked products and fulfills customers' requests for good nourishment and diversity in food items (Alvarez-Jubete et al., 2010).

However, this substitution will change rheological properties of the dough, and the bakery products quality. It is notable that proteins in non-wheat flours lack the capacity to shape the gluten network in charge of holding the gas created through the leavening (Gallagher et al., 2003).

Quinoa (Chenopodium quinoa) is an endemic crop of the Andean region. It has been recognized as a very nutritious grain, due to the good quality and quantity of its protein and essential fatty acids (Hager et al., 2012). Essential amino acid (EAA) content of quinoa has likewise been observed to be more than that of wheat flour (Stikic et al., 2012); especially, lysine (a limiting amino acid for cereals) which was observed to be two times higher than wheat flour. According to the USDA 
Egyptian J. of Nutrition Vol. XXXIV No. 2 (2019)

nutrient database (2014), quinoa flour composed of $6.07 \%$ total lipid, $14.12 \%$ protein, $64.16 \%$ carbohydrate and $7 \%$ dietary fiber.

Among various rheological procedures, Mixolab mechanical assembly has been utilized in numerous studies for testing behavior of the dough through production conditions (Huang et al., 2010). By using Mixolab it is conceivable to identify the mechanical changes due to blending and warming recreating the mechanical work just as the conditions that might be used through the baking process. The favorable aspect of using Mixolab is that one test can gauge properties of starch and proteins (and related enzymes).

The aim of this search was to investigate the impact of substitution of wheat flour by of quinoa seeds flour at 5,10 , and $15 \%$ on: (1) the nutritional quality of produced pan bread, (2) dough rheological properties prepared from blends of wheat and quinoa flours.

\section{Materials and Methods}

\section{Materials}

Wheat flour (WF) (72\% extraction) and other ingredients used for pan bread making were obtained from the local market. Quinoa seeds (Chenopodium quinoa Willd.) were obtained from Agriculture Research Center, Giza, Egypt. 


\section{Mohamed E. Abdel-Aziz}

Methods

\section{Quinoa flour preparation}

The quinoa seeds were washed several times with water to eliminate saponins until there was no more froth in the washing water, and then dried at $50^{\circ} \mathrm{C}$. The quinoa seeds were grinding to fine powder in an electric mill sieved through a 60 mesh and stored at $4{ }^{\circ} \mathrm{C}$ until used.

\section{Preparation of wheat/quinoa flour blends}

The following flour blends were prepared: $95 \mathrm{~g}$ of wheat flour+ $5 \mathrm{~g}$ of quinoa flour, $90 \mathrm{~g}$ of wheat flour $+10 \mathrm{~g}$ of quinoa flour and $85 \mathrm{~g}$ of wheat flour+ $15 \mathrm{~g}$ of quinoa flour. The control bread was prepared with wheat flour. The flour quantities were related to $100 \mathrm{~g}$ of blend dry matter.

\section{Production of pan breads}

Bread making of all bread blends followed the procedures described by Schmiele et al. (2012).

\section{Determination of rheological properties of the flour blends}

The rheological behavior of the dough of wheat flour and its blends with quinoa flour was analyzed using Mixolab "Chopin+" protocol according to AACC (2005) method 5460.01. Mixolab was used according to the method described by (Chopin, 2009) to measure water absorption (C1), protein weakening (C2), starch gelatinization (C3), amylase action (C4) and starch retrogradation (C5) characteristics of the flour. The calculated amount of wheat flour (from the apparatus 
Egyptian J. of Nutrition Vol. XXXIV No. 2 (2019)

programming) was put into the Mixolab bowl and exposed to hydration, blending and heating as indicated by the standard Chopin+ convention, with a setting of $80 \mathrm{rpm}$ blending rate, 75 $\mathrm{g}$ dough weight, $30^{\circ} \mathrm{C}$ tank temperature and a total analysis period of $45 \mathrm{~min}$.

\section{Chemical composition of pan bread}

Ash, crude fiber, protein and fat contents were determined according to methods described in AOAC (2005). Nitrogen free extract (NFE) was calculated by difference.

\section{Physical characteristics of pan bread}

The specific volume of pan bread loaves was determined according to AACC (2005). The loaves were weighed in a semi- analytical balance and the volume measured by rapeseed displacement. The specific volume in $\mathrm{cm}^{3} / \mathrm{g}$ was calculated from the relationship of volume to weight ratio.

\section{Color of pan bread}

The color of crust and crumb pan bread were measured using a Minolta colorimeter (Chroma Meter CR400/410, Konica Minolta, Japan), where three readings were taken for each sample (Minolta, 1994).

\section{Total phenolic content and antioxidant activity}

Total phenolic content (TPC) of wheat flour, quinoa flour and pan bread samples and DPPH (1, 1-diphenyl-2- 


\section{Mohamed E. Abdel-Aziz}

picrylhydrazyl) radical scavenging activity were determined according to Lucini et al. (2015a).

\section{Sensory evaluation of pan bread}

Control pan bread (100\% wheat flour) and pan bread containing QF at different levels were sensory evaluated by 20 panelists from the staff members of Food Science Department, Faculty of Agriculture, Cairo University. The panelists were asked to evaluate color, appearance, odor, taste, texture and overall acceptability. Pan bread samples were evaluated using a 9-point hedonic scale, where (1=dislike extremely, 2=dislike very much, $3=$ dislike moderately, $4=$ dislike slightly, $5=$ neither like nor dislike, 6=like slightly, 7=like moderately, 8=like very much, and $9=$ like extremely) as outlined by Ihekoronye and Ngoddy (1985).

\section{Statistical analysis}

All of the experimental data were performed in triplicate and the results were expressed as mean \pm standard deviation. Analysis of variance was performed by one way ANOVA test and a statistically significant $(p<0.05)$ was considered.

\section{Results and Discussion}

\section{Rheological properties of composite flour}

Mixolab was applied to test the characteristics of wheat flour (72\% extraction) and its blends with quinoa flour and the obtained results are appeared in Table (1). 
Egyptian J. of Nutrition Vol. XXXIV No. 2 (2019)

Water absorption, stability and mechanical debilitating are parameters which point to dough properties through blending at steady temperature $\left(30^{\circ} \mathrm{C}\right)$, depicting the dough behavior during production stage. Through blending hydration of the mixes and the extending and arrangement of the proteins happens, which led to the development of a 3 dimensional viscoelastic structure (Bonet et al., 2006). The Mixolab tests were carried out for each sample at $14 \%$ moisture basis. The water amount was added to guarantee dough kneading opposition of torque $1.10 \mathrm{~N} . \mathrm{m}$ which represent dough consistency 500 Brabender units (BU).

The wheat flour (72\% extraction) need water absorption of $55 \%$ ( $14 \%$ moisture content) to arrive a torque of $1.11 \mathrm{Nm}$. Moreover, addition of quinoa flour at $5 \%$ to wheat flour led to slightly reduction in water absorption by $0.18 \%$. Water absorption increased by 1.09 and $2.36 \%$ by the addition of quinoa flour at 10 and $15 \%$, respectively.

Quinoa flour mixes had essentially higher water retention. The expansion of amylase action through the washing and drying process and through the preparation of flour could influence the conduct of quinoa flour hydration demonstrating that these flours require water and longer period to hydrate each of the mixes than wheat flour (Ahamed et al., 1996). 


\section{Mohamed E. Abdel-Aziz}

The $\mathrm{C} 1$ parameter of wheat flour (control sample) was 1.07 which was significantly lower than that of $5 \%$ quinoa blend by $5.61 \%$. Blends of 10 and $15 \%$ quinoa flour showed no significant difference from the control sample. At the point when the temperature of the dough was raised from $30{ }^{\circ} \mathrm{C}$ at a rate of $4^{\circ} \mathrm{C} / \mathrm{min}$, the gluten weakening happened and dough consistency reduce till C2 was arrived. The W90/Q10 and W85/Q15 blends showed lower values of C2 than the control sample (Table 1). The C2 value of wheat flour was $0.48 \mathrm{Nm}$, whereas it decreased by $6.25 \%$ for W90/Q10 and W85/Q15 blends. Meanwhile, the C2 increased for W95/Q5 by 6.25 $\%$.The dough temperature of wheat flour at $\mathrm{C} 2$ was $53.2^{\circ} \mathrm{C}$ whereas it was $53.5^{\circ} \mathrm{C}$ for W95/Q5 blend, $53.9^{\circ} \mathrm{C}$ for W90/Q10 blend and $55.4{ }^{\circ} \mathrm{C}$ for W85/Q15 blend. This indicated that the wheat flour and W95/Q5 blend started to gelatinize at a lower temperature than others.

These results showed that with increasing temperature and blending stress, the strength of dough decreased as a result of gluten weakening. As heating proceeded, protein changes have minor influence and the starch granules have predominant role in torque increase (Rosell et al., 2007).

The raise in viscosity and so in the torque is the consequence of the starch granules distention because of the water absorption and amylose chains leaking into the fluid intergranular phase (Rosell et al., 2009). Wheat flour participate in a best starch performance of the blends (higher 
Egyptian J. of Nutrition Vol. XXXIV No. 2 (2019)

starch gelatinization, C3) than mixes, whereas the starch gelatinization of blends decreased by $3.45,7.39$ and $12.81 \%$ for W95/Q5, W90/Q10 and W85/Q15 blends, respectively.

Moreover, significant differences were observed between all samples for $\mathrm{C} 4$ values which decreased by increasing quinoa flour level in the blends. The further decrease in viscosity (C4) is the after-effect of the physical breakdown of the granules because of the mechanical shear stress and the temperature limitation (Rosell et al., 2007).

Quinoa flours exhibited the lowest breakdown torques. Thereafter, on cooling, starch retrograded and the consistency decreased (C5). The C5 values decreased by $23.71 \%, 31.96 \%$ and $41.24 \%$ for W90/Q5, W90/Q10 and W85/Q15, respectively. Lower retrogradation might be related with expanded shelf life of bread as reported by Collar et al. (2007). Increasing quinoa flour level increased bread firmness during storage.

\section{Chemical composition of pan bread containing QF:}

Proximate chemical composition of pan bread samples is listed in Table (2).

Protein content of pan bread increased with increasing the quinoa flour \% from $12.12 \pm 0.63 \%$ in the control to $14.78 \pm 0.02 \%$ in the sample containing $15 \%$ quinoa flour. This could be due to the high protein content in quinoa flour $(20.03 \%)$. Fat, crude fiber and ash contents of pan bread 


\section{Mohamed E. Abdel-Aziz}

containing quinoa were likewise higher than their contents in control. The N.F.E content in the bread containing quinoa flour was lower than control sample. These results are in accordance with Stikic et al. (2012) who stated that pan bread prepared with different percentages of quinoa flour have high nutritive value.

\section{Physical characteristics of pan bread}

Physical characteristics of pan bread, such as volume, weight and specific volume, were affected by the increase in the level of quinoa flour as presented in Table (3).

The changes in weight and volume values are reflected in specific volume which reliably diminished from 3.61 for control bread to 2.80 for bread containing $15 \%$ quinoa flour. The weight, volume and specific volume of the prepared pan bread were oppositely influenced by quinoa level. This decrease in pan bread volume with the increase the level of quinoa flour might be due to its high level of resistant starch.

All loaves samples were significantly different $(P \leq 0.05)$ for their specific volume (Table 3 ). Increasing the substitution of wheat flour with quinoa flour significantly $(P<0.05)$ resulted in reduction in the specific volume of the prepared bread. Such reduction in the specific volume could be due to pseudocereals that does not contain gluten (Gorinstein et al., 2008). 
Egyptian J. of Nutrition Vol. XXXIV No. 2 (2019)

Additionally, interaction between protein (gluten) in wheat flour and fiber in the bread can prohibit its expansion during fermentation, leaving the bread denser with a little volume (Blandino et al., 2003).

\section{Color quality of pan bread}

The color parameters of pan bread samples are shown in Table 4. Increasing the quinoa flour in the composites resulted in a decrease the crust lightness $(L)$ of prepared bread significantly. The lightness $(L)$ value of the control was $73.38 \pm 0.56$, whereas, it was $68.77 \pm 0.68$ in the crust of pan bread made from $15 \%$ quinoa flour. Samples with higher levels of quinoa flour had darker crust due to the dark color of the quinoa flour and as well increasing protein with lysine residues and reducing sugars contents that react during baking producing non-enzymatic maillard browning.

The (a) value of crust bread was increased by increasing quinoa flour in the blend. The (a) value in control sample recorded $2.87 \pm 0.14$ while it was $4.38 \pm 0.78$ in bread containing $15 \%$ quinoa flour.

The yellowness value (b) of crust was significantly increased with increasing quinoa flour level. The (b) value of the control was $22.70 \pm 0.94$, while bread containing $15 \%$ quinoa flour was $25.15 \pm 2.57$. These results are near to the previous results by Stikic et al. (2012) who found that the bread containing 10, 15 and $20 \%$ quinoa flour had yellow-reddish 


\section{Mohamed E. Abdel-Aziz}

crispy crust. Similarly, Wang et al. (2017) found that darkness and redness of bread was increased when the amount of quinoa flour increased in the flour composite. This was due to the high protein content in quinoa flour, which brought about the maillard browning during baking.

The color bread crumb containing different percentages of quinoa flour are presented in Table (4). The lightness (L) value showed significant decrease with proportion of quinoa flours increase, resulted in darker crumbs in pan bread. The $(L)$ value of the control was $66.5 \pm 0.03$, while in bread containing $15 \%$ quinoa flour was $64.28 \pm 0.22$. The redness value (a) was significantly increased with increasing the quinoa flours in the blends compared to control.

The (a) value of the control was $1.38 \pm 0.02$ whereas in bread containing $15 \%$ quinoa flour was $3.12 \pm 0.08$. The (b) value also significantly increased when the quinoa flour increased in the composites compared to control. The (b) value of the control was $19.67 \pm 0.19$, whereas in bread containing $15 \%$ quinoa flour was $24.58 \pm 0.36$. The lightness $(L)$ value of crumb was lower in bread containing quinoa flour, whereas (a) and (b) values were higher for bread containing quinoa flour compared to the control (Lorenz et al., 1995).

\section{Total phenolic content and antioxidant activity}

Total phenolic content (TPC) for wheat flour, and QF was 56.5 and $78.6 \mathrm{mg}$ Gallic acid equivalent/ 100g (mg 
Egyptian J. of Nutrition Vol. XXXIV No. 2 (2019)

GAE/100g), respectively. DPPH scavenging activity of wheat flour was $13.8 \%$ while it reached $38.6 \%$ in the QF (Table 5). Control bread contained the lowest TPC content $(30.7 \mathrm{mg}$ GAE/100g) while, breads made from 5, 10 and $15 \%$ QF had higher TPC content of $37.8,46.1$ and $55.4 \mathrm{mg} \mathrm{GAE} / 100 \mathrm{~g}$, respectively. Total phenolic content in all breads was lower than its respective flour.

QF enhanced DPPH scavenging activity percentages of bread samples compared to control bread. Similar results were found by Swieca et al. (2014) who concluded that antioxidant activity increase with the addition of quinoa seeds powder to the bread formula.

\section{Sensory Evaluation of prepared pan bread}

The loaves were exposed to sensory evaluation by the 9-point hedonic scale test, and the results are appeared in Table (6). No significant differences in the crust and crumb color, crumb appearance and overall acceptability parameters analyzed between the control pan bread (wheat flour $72 \%$ extraction) and the samples with quinoa flour.

The results in Table (6) indicated that crust color of control bread and bread samples contained $5 \%$ QF showed like moderately quality grade, while that contained $10 \%$ and $15 \%$ QF showed like slightly quality grade. Also, crumb color of control bread and bread samples contained 5\% QF showed like moderately quality grade, while that contained $10 \%$ and $15 \%$ 


\section{Mohamed E. Abdel-Aziz}

QF showed like slightly quality grade. The same trend was observed in crumb appearance of control bread and bread samples contained QF. There were a significant differences in the taste and odor parameters analyzed between the control pan bread (wheat flour $72 \%$ extraction) and the samples with quinoa flour. Taste and odor of control bread and bread samples contained 5 and 10\% QF showed like moderately quality grade, while that contained 15\% QF showed like slightly quality grade.

The data also showed that flavor had higher score in case of control, which resulted in good acceptance (like very much). Blends contained 5, 10, and $15 \%$ of quinoa flour showed scores ranged between 7.40 to 6.42 for taste and 7.50 to 6.36 for odor, which are also accepted organoleptically.

Adding quinoa flour to wheat flour for making pan bread, it is critical to take note of that very amazing flavor of quinoa was perceived in each loaves of pan bread contained quinoa flour.

The overall acceptability in control pan bread was $8.76 \pm$ 1.53 while in $15 \%$ QF it was $6.50 \pm 1.31$. This decrease in overall acceptability is expected to dark color of loaves made from different ratio of quinoa flour. The substitution of wheat flour by quinoa flour could cause changes in the sensory attributes of products. 
Egyptian J. of Nutrition Vol. XXXIV No. 2 (2019)

\section{Conclusions}

The pan bread containing different levels of quinoa flour $(5 \%, 10 \%$, and $15 \%)$ increased its levels of protein, fat, crude fiber, and ash. The physical properties of the bread were changed by adding quinoa flour to wheat flour $72 \%$ extraction. The supplement of quinoa flour did not drastically influence the rheological qualities of dough. Replacement of wheat flour with quinoa flour slightly affected rheological qualities and did not cause distorting of dough. In this way, these impacts can be ignored contrasted with the raising of the healthy benefits. Sensory evaluation of bread showed high acceptability even at $15 \%$ supplementation level. The addition of quinoa flour to wheat flour improved effectively antioxidant status of pan bread. 
Mohamed E. Abdel-Aziz

Table (1): Mixolab parameters of wheat flour (W) and wheat flour /quinoa flour blends

\begin{tabular}{l|c|c|c|c|c|c|c}
\hline Treatments & C 1 & C 2 & Stability & C 3 & C 4 & C 5 & Alpha \\
\hline $\begin{array}{l}\text { W } \\
\text { (Control) }\end{array}$ & $1.07^{\mathrm{b}}$ & $0.48^{\mathrm{ab}}$ & $11.05^{\mathrm{b}}$ & $2.03^{\mathrm{a}}$ & $1.87^{\mathrm{a}}$ & $2.91^{\mathrm{a}}$ & $0.0043^{\mathrm{a}}$ \\
\hline W95/Q5 & $1.13^{\mathrm{a}}$ & $0.51^{\mathrm{a}}$ & $11.10^{\mathrm{a}}$ & $1.96^{\mathrm{ab}}$ & $1.57^{\mathrm{b}}$ & $2.22^{\mathrm{b}}$ & $-0.1240^{\mathrm{d}}$ \\
\hline W90/Q10 & $1.08^{\mathrm{b}}$ & $0.45^{\mathrm{b}}$ & $10.78^{\mathrm{c}}$ & $1.88^{\mathrm{b}}$ & $1.41^{\mathrm{c}}$ & $1.98^{\mathrm{c}}$ & $-0.0323^{\mathrm{b}}$ \\
\hline W85/Q15 & $1.08^{\mathrm{b}}$ & $0.45^{\mathrm{b}}$ & $10.68^{\mathrm{d}}$ & $1.77^{\mathrm{c}}$ & $1.19^{\mathrm{d}}$ & $1.71^{\mathrm{d}}$ & $-0.0107^{\mathrm{c}}$ \\
\hline
\end{tabular}

Means with the same letter in the same column are not significantly different $(\mathrm{p}<0.05)$

W (Control $100 \%$ wheat flour), W95/Q5 (sample containing $95 \%$ of wheat flour and $5 \%$ of quinoa flour), W90/Q10 (sample containing $90 \%$ of wheat flour and $10 \%$ of quinoa flour), W85/Q15 (sample containing $85 \%$ of wheat flour and $15 \%$ of quinoa flour)

Table (2): Chemical composition of pan bread containing quinoa flour (on dry weight basis)

\begin{tabular}{l|c|c|c|c|c}
\hline Treatments & Protein & Fat & $\begin{array}{c}\text { Crude } \\
\text { fiber }\end{array}$ & Ash & N.F.E \\
\hline W (Control) & $12.12^{\mathrm{d}}$ & $1.19^{\mathrm{d}}$ & $0.54^{\mathrm{d}}$ & $1.58^{\mathrm{d}}$ & $84.56^{\mathrm{a}}$ \\
& \pm 0.63 & \pm 0.03 & \pm 0.07 & \pm 0.09 & \pm 0.18 \\
\hline \multirow{2}{*}{ W95/Q5 } & $13.71^{\mathrm{c}}$ & $1.39^{\mathrm{c}}$ & $0.66^{\mathrm{c}}$ & $2.11^{\mathrm{c}}$ & $82.11^{\mathrm{b}}$ \\
& \pm 0.06 & \pm 0.02 & \pm 0.05 & \pm 0.08 & \pm 0.11 \\
\hline \multirow{2}{*}{ W90/Q10 } & $14.36^{\mathrm{b}}$ & $1.68^{\mathrm{b}}$ & $0.85^{\mathrm{b}}$ & $2.31^{\mathrm{b}}$ & $80.80^{\mathrm{c}}$ \\
& \pm 0.21 & \pm 0.02 & \pm 0.06 & \pm 0.04 & \pm 0.12 \\
\hline \multirow{2}{*}{ W85/Q15 } & $14.78^{\mathrm{a}}$ & $1.87^{\mathrm{a}}$ & $1.05^{\mathrm{a}}$ & $2.68^{\mathrm{a}}$ & $79.61^{\mathrm{d}}$ \\
& \pm 0.02 & \pm 0.03 & \pm 0.04 & \pm 0.03 & \pm 0.03 \\
\hline
\end{tabular}

Means with different letters in the same column indicate significant differences (PS 0.05).

W (Control $100 \%$ wheat flour), W95/Q5 (sample containing $95 \%$ of wheat flour and $5 \%$ of quinoa flour), W90/Q10 (sample containing $90 \%$ of wheat flour and $10 \%$ of quinoa flour), W85/Q15 (sample containing $85 \%$ of wheat flour and $15 \%$ of quinoa flour) 
Egyptian J. of Nutrition Vol. XXXIV No. 2 (2019)

Table (3): Physical characteristics of pan bread containing quinoa flour

\begin{tabular}{l|c|c|c}
\hline Treatments & Weight $(\mathrm{g})$ & volume $\left(\mathrm{cm}^{3}\right)$ & $\begin{array}{c}\text { Specific volume } \\
\left(\mathrm{cm}^{3} / \mathrm{g}\right)\end{array}$ \\
\hline $\mathrm{W}$ (Control) & $87.30^{\mathrm{a}} \pm 1.56$ & $315.20^{\mathrm{a}} \pm .3 .02$ & $3.61^{\mathrm{a}} \pm 0.01$ \\
\hline W95/Q5 & $87.40^{\mathrm{a}} \pm 2.12$ & $301.50^{\mathrm{b}} \pm 2.90$ & $3.45^{\mathrm{b}} \pm 0.06$ \\
\hline W90/Q10 & $87.03^{\mathrm{b}} \pm 1.19$ & $288.90^{\mathrm{c}} \pm 1.90$ & $3.32^{\mathrm{c}} \pm 0.01$ \\
\hline W85/Q15 & $86.25^{\mathrm{c}} \pm 1.38$ & $242.36^{\mathrm{d}} \pm 2.70$ & $2.80^{\mathrm{d}} \pm 0.05$ \\
\hline
\end{tabular}

Means with different letters in the same column indicate significant differences (P $\leq$ 0.05).

W (Control $100 \%$ wheat flour), W95/Q5 (sample containing $95 \%$ of wheat flour and $5 \%$ of quinoa flour), W90/Q10 (sample containing $90 \%$ of wheat flour and $10 \%$ of quinoa flour), W85/Q15 (sample containing $85 \%$ of wheat flour and $15 \%$ of quinoa flour)

Table (4): Color quality of pan bread samples as affected by quinoa flour

\begin{tabular}{l|c|c|c|c|c|c}
\hline \multirow{2}{*}{ Treatments } & \multicolumn{2}{|c|}{ Lightness "L" } & \multicolumn{2}{c|}{ Redness "a" } & \multicolumn{2}{c}{ Yellowness "b" } \\
\cline { 2 - 7 } & Crust & Crumb & Crust & Crumb & Crust & Crumb \\
\hline \multirow{2}{*}{ W (Control) } & $73.38^{\mathrm{a}}$ & $66.5^{\mathrm{a}}$ & $2.87^{\mathrm{b}}$ & $1.38^{\mathrm{d}}$ & $22.70^{\mathrm{b}}$ & $19.67^{\mathrm{d}}$ \\
& \pm 0.56 & \pm 0.03 & \pm 0.14 & \pm 0.02 & \pm 0.94 & \pm 0.19 \\
\hline \multirow{2}{*}{ W95/Q5 } & $72.32^{\mathrm{a}}$ & $66.15^{\mathrm{b}}$ & $3.08^{\mathrm{b}}$ & $1.75^{\mathrm{c}}$ & $23.93^{\mathrm{a}}$ & $22.43^{\mathrm{c}}$ \\
& \pm 0.35 & \pm 0.06 & \pm 0.02 & \pm 0.08 & \pm 0.45 & \pm 0.08 \\
\hline \multirow{2}{*}{ W90/Q10 } & $70.37^{\mathrm{b}}$ & $66.53^{\mathrm{a}}$ & $4.67^{\mathrm{a}}$ & $2.32^{\mathrm{b}}$ & $24.85^{\mathrm{a}}$ & $23.72^{\mathrm{b}}$ \\
& \pm 0.53 & \pm 0.09 & \pm 0.55 & \pm 0.04 & \pm 1.21 & \pm 0.14 \\
\hline \multirow{2}{*}{ W85/Q15 } & $68.77^{\mathrm{c}}$ & $64.28^{\mathrm{c}}$ & $4.38^{\mathrm{a}}$ & $3.12^{\mathrm{a}}$ & $25.15^{\mathrm{a}}$ & $24.58^{\mathrm{a}}$ \\
& \pm 0.68 & \pm 0.22 & \pm 0.78 & \pm 0.08 & \pm 0.5 & \pm 0.36 \\
\hline
\end{tabular}

Means with different letters in the same column indicate significant differences ( $P \leq$ 0.05).

W (Control $100 \%$ wheat flour), W95/Q5 (sample containing $95 \%$ of wheat flour and $5 \%$ of quinoa flour), W90/Q10 (sample containing $90 \%$ of wheat flour and $10 \%$ of quinoa flour), W85/Q15 (sample containing $85 \%$ of wheat flour and $15 \%$ of quinoa flour) 
Mohamed E. Abdel-Aziz

Table (5): Total phenolic content and antioxidant activity of wheat flour, quinoa flour and prepared pan bread

\begin{tabular}{l|c|c}
\hline Samples & $\begin{array}{c}\text { TPC } \\
\text { mg Gallic acid equivalent/100 g }\end{array}$ & $\begin{array}{c}\text { DPPH Scavenging } \\
\text { activity } \%\end{array}$ \\
\hline Wheat flour & $56.5 \pm 1.05^{\mathrm{b}}$ & $13.8 \pm 0.2^{\mathrm{c}}$ \\
\hline Quinoa flour & $78.6 \pm 1.19^{\mathrm{a}}$ & $38.6 \pm 0.1^{\mathrm{a}}$ \\
\hline Pan breads & & \\
\hline W (Control) & $30.7 \pm 0.09^{\mathrm{d}}$ & $9.25 \pm 0.2^{\mathrm{d}}$ \\
\hline W95/Q5 & $37.8 \pm 0.07^{\mathrm{d}}$ & $12.3 \pm 0.7^{\mathrm{c}}$ \\
\hline W90/Q10 & $46.1 \pm 0.10^{\mathrm{c}}$ & $14.9 \pm 0.3^{\mathrm{c}}$ \\
\hline W85/Q15 & $55.4 \pm 0.08^{\mathrm{b}}$ & $17.5 \pm 0.4^{\mathrm{b}}$ \\
\hline
\end{tabular}

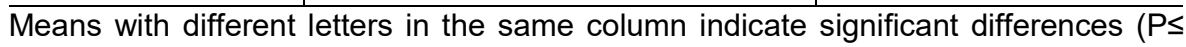
0.05).

W (Control $100 \%$ wheat flour), W95/Q5 (sample containing $95 \%$ of wheat flour and $5 \%$ of quinoa flour), W90/Q10 (sample containing $90 \%$ of wheat flour and $10 \%$ of quinoa flour), W85/Q15 (sample containing $85 \%$ of wheat flour and $15 \%$ of quinoa flour)

Table (6): Sensory evaluation of quinoa flour-based pan bread

\begin{tabular}{l|c|c|c}
\hline Treatments & Crust color & Crumb color & Crumb appearance \\
\hline W (Control) & $7.42 \pm 1.14^{\mathrm{a}}$ & $7.50 \pm 1.28^{\mathrm{a}}$ & $7.28 \pm 1.28^{\mathrm{a}}$ \\
\hline W95/Q5 & $7.10 \pm 1.31^{\mathrm{b}}$ & $7.22 \pm 1.37^{\mathrm{b}}$ & $7.00 \pm 1.54^{\mathrm{b}}$ \\
\hline W90/Q10 & $6.72 \pm 1.49^{\mathrm{c}}$ & $6.80 \pm 1.28^{\mathrm{c}}$ & $6.82 \pm 1.22^{\mathrm{c}}$ \\
\hline W85/Q15 & $6.16 \pm 1.63^{\mathrm{d}}$ & $6.04 \pm 1.47^{\mathrm{d}}$ & $6.86 \pm 1.40^{\mathrm{c}}$ \\
\hline Treatments & Taste $^{\mathrm{a}}$ & Odor & Overall Acceptability $^{\mathrm{W}}$ \\
\hline W (Control) & $7.84 \pm 1.60^{\mathrm{a}}$ & $7.82 \pm 1.47^{\mathrm{a}}$ & $8.76 \pm 1.53^{\mathrm{a}}$ \\
\hline W95/Q5 & $7.40 \pm 1.80^{\mathrm{b}}$ & $7.50 \pm 1.64^{\mathrm{b}}$ & $7.94 \pm 1.57^{\mathrm{b}}$ \\
\hline W90/Q10 & $7.06 \pm 1.74^{\mathrm{c}}$ & $7.00 \pm 1.65^{\mathrm{c}}$ & $7.00 \pm 1.47^{\mathrm{c}}$ \\
\hline W85/Q15 & $6.42 \pm 1.64^{\mathrm{d}}$ & $6.36 \pm 1.83^{\mathrm{d}}$ & $6.50 \pm 1.31^{\mathrm{d}}$
\end{tabular}

Means with different letters in the same column indicate significant differences ( $\mathrm{P} \leq$ 0.05).

W (Control $100 \%$ wheat flour), W95/Q5 (sample containing $95 \%$ of wheat flour and $5 \%$ of quinoa flour), W90/Q10 (sample containing $90 \%$ of wheat flour and $10 \%$ of quinoa flour), W85/Q15 (sample containing $85 \%$ of wheat flour and $15 \%$ of quinoa flour) 
Egyptian J. of Nutrition Vol. XXXIV No. 2 (2019)

\section{References}

A.A.C.C. (2005).

Approved Method of the American Association of Cereal Chemists, $11^{\text {th }}$ ed. INC. St. Paul, Minnesota, USA.

A.O.A.C. (2005).

Official methods of analysis of the association of official analytical chemists, $18^{\text {th }}$ ed., AOAC International, Arlington, Virginia, USA.

Ahamed, N. T.; Singhal, R. S.; Kulkami, P. R. and Palb, M. (1996).

Physicochemical and functional properties of Chenopodium quinoa starch. Carbohydrate Polymers, 31: 99-103.

Alvarez-Jubete, L.; Auty, M.; Arendt, E. K. and Gallagher, E. (2010).

Baking properties and microstructure of pseudocereal flours in gluten-free bread formulations. Eur. Food Res. Technol. 230: 437-445.

Blandino, A.; Al-Aseeri, M. E.; Pandiella, S. S.; Cantero, D. and Webb, C. (2003).

Cereal-based fermented foods and beverages. Food Research International, 36(6):527-543. 


\section{Mohamed E. Abdel-Aziz}

Bonet, A.; Cristina, M. R. and Caballero, P. A. (2006). Glucose oxidase effect on dough rheology and bread quality: A study from macroscopic to molecular level. Food Chemistry, 99 (2):408-415.

Chopin (2009).

Mixolab Applications Handbook. Chopin Technologies Publication, France. pp. 9-16.

Collar, C.; Bollain, C. and Rosell, C. M. (2007).

Rheological behaviour of formulated bread doughs during mixing and heating. Food Science and Technology International, 13 (2): 99-107.

Gallagher, E.; Gormley, T. R. and Arendt, E. K. (2003).

Crust and crumb characteristics of gluten free breads. Journal of Food Engineering, 56: 153-161.

Gorinstein, S.; Lojek, A.; Ciz, M.; Pawelzik, E.; DelgadoLicon, E. and Medina, O. J. (2008).

Comparison of composition and antioxidant capacity of some cereals and pseudocereals. International Journal of Food Science and Technology, 43:629-637. 
Egyptian J. of Nutrition Vol. XXXIV No. 2 (2019)

Hager, A. S.; Anika, W.; Fritz, J.; Emanuele, Z. and Elke, K. A. (2012).

Nutritional properties and ultra-structure of commercial gluten free flours from different botanical sources compared to Wheat flours. Journal of Cereal Science, 56: 239-247.

Huang, W. N.; Li, L. L.; Wang, F.; Wan, J. J. and Tilley, M. (2010).

Effect of transglutaminase on rheological and mixolab thermomechanical characteristics of oat dough. Food Chemistry, 121: 934-939.

Ihekoronye, A. I. and Ngoddy, P.O. (1985).

Integrated Food Science and Technology. Macmilian Publishers, New York. Pp: 296-301.

Lorenz, K.; Coulter, L. and Johnson, D. (1995).

Functional and sensory characteristics of quinoa in foods. Developments in Food Science, 37: 1031-1041.

Lucini, L., Pellizzoni, M., Pellegrino, R., Molinari, G. P., \& Colla, G. (2015a).

Phytochemical constituents and in vitro radical scavenging activity of different Aloe species. Food Chemistry, 170: 501-507. 


\section{Mohamed E. Abdel-Aziz}

MINOLTA. (1994).

Precise color communication: color control from feeling to instrumentation, p. 49, Minolta Co. Ltd., Osaka, Japan.

USDA- United States Department of Agriculture (2014).

National Nutrient Database for Standard Reference Release, 27, p. 20035 (Quinoa- uncooked, and Buckwheat).

Rosell, C. M.; Collar, C. and Haros, M. (2007).

Assessment of hydrocolloid effects on the thermomechanical properties of wheat using the Mixolab. Food Hydrocolloids, 21: 452-462.

Rosell, C. M.; Cortez, G. and Repo-Carrasco, R. (2009). Bread making use of Andean crops quinoa, Kañiwa, kiwicha and tarwi. Cereal Chemistry, 84 (4): 386-392.

Sabanis, D.; Lebesi, D. and Tzia, C. (2009).

Effect of dietary fiber enrichment on selected properties of gluten-free bread. LWT- Food Science and Technology, 42(8):1380-1389. 
Egyptian J. of Nutrition Vol. XXXIV No. 2 (2019)

Schmiele, M.; Jaekel, L. Z.; Patricio, S. M. C.; Steel, C. J. and Chang, Y. K. (2012).

Rheological properties of wheat flour and quality characteristics of pan bread as modified by partial additions of wheat bran or whole grain wheat flour. International Journal of Food Science and Technology, 47(10): 2141-2150.

Stikic, R.; Djordje, G.; Mirjana, D.; Biljana, V. R.; Zorica, J.; Dusanka, M. O. and Mirjana, M. (2012).

Agronomical and nutritional evaluation of quinoa seeds (Chenopodium quinoa Willd.) as an ingredient in bread formulations. Journal of Cereal Science, 55: 132-138.

Swieca, M.; Seczyk, L.; Dziki, U. G. and Dziki, D. (2014). Bread enriched with quinoa leaves: the influence of protein-phenolics interactions on the nutritional and antioxidant quality. Food Chemistry, 162: 54-62.

Wang, N.; Anfu, H.; Joseffus, S. and Lisa, M. (2017).

Effects of cultivar, growing location, and year on physicochemical and cooking characteristics of dry beans (Phaseolus vulgaris). Cereal Chemistry, 94(1): 128-134. 


\section{Mohamed E. Abdel-Aziz}

متغيرات جهاز الميكسولاب لخليط دقيق القمح/الكينوا وعلاقته بخصائص الجودة

محمد عماد الدين عبد العزيز

قسم الصناعات الذذائية ـ كلية الزراعة - جامعة القاهرة - الجيزة - مصر

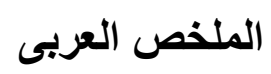

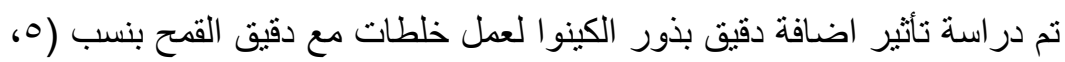
• (1 10 \%) على كل من خصائص العجن، الخصائص الفيزيائية، الخصائص الحسية

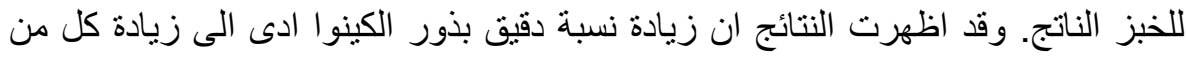

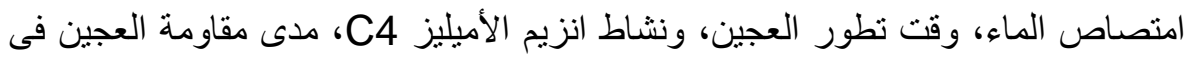

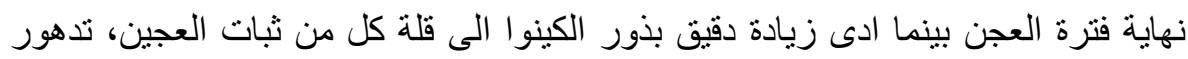

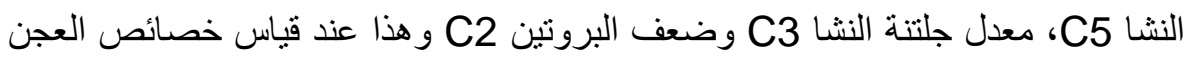

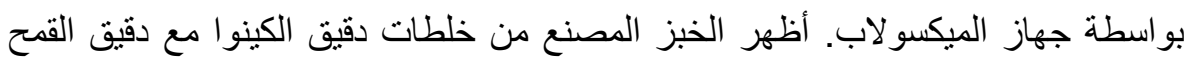

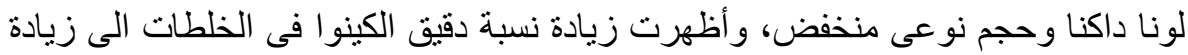

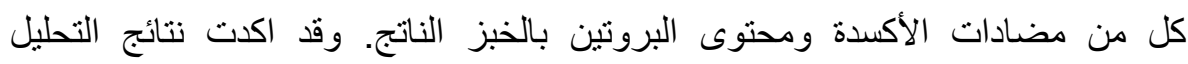

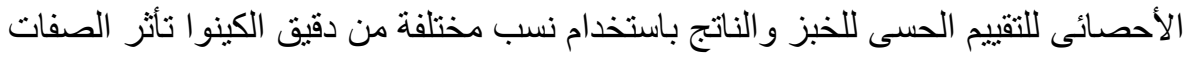
الحسية بارتفاع النسبة المستخدمة الا انها ما زالت تحظى بالقبول لدى المستهلك. 